\title{
Education Ecology and Web-based Course Development
}

\author{
Ling Zhang ${ }^{1, \text { a }}$ \\ ${ }^{1}$ Beijing Wuzi University, Beijing, China \\ arene_zhangling@hotmail.com
}

Keywords: Education ecology; Network course construction; Life-long learning.

\begin{abstract}
Education ecology theory should be introduced to web-course construction in order to further the development of web-based courses. Firstly, web-courses should be treated as a micro education ecological system, and ecological factors in the system should be analyzed, such as ecological environment, ecological information, and the mainstay. Then, an open, diverse, harmonious and sustainable course should be established in order to achieve the lifelong learning of learners.
\end{abstract}

\section{Introduction}

With the deepening of the educational informationization and the advent of lifelong learning, network curriculum development obtains more attention from educators. However, many problems still exists in present network course construction, such as the design base is unclear and learning subjects are overlooked in network learning. Course contents are monotonously designed. Attention on the design of the network learning environment is not enough. As a type of micro education ecological system, web courses consists of three ecological factors: ecological environment, ecological information, and the mainstay. Ecological subjects include learners and instructors. Ecological information includes learning concepts, learning contents, and learning methods. And there are two parts in Ecological environment---material environment and spiritual environment[1]. Education ecology requires that ecological environment, ecological information, and subjects be treated as a complete system of teaching. Hence, an open, diverse, harmonious and sustainable course form will be established.

\section{Brief Introduction to the Education Ecology}

Overview of education ecology. In 1976, the president of Teachers College of Columbia University Lawrence Cremm put forward the concept of education ecology in the book of Public Education. The concept of ecology was introduced to education for the first time. Education ecology is an interdisciplinary subject emerged in the 1970s. This subject mainly studies various education phenomenon and causes, and the interaction between education and surrounding ecological environment. At present, basic views and theory system of research concerning education ecology is still in the early phase of formation and exploration. there are still different views and gaps with this subject. Lawrence Cremm held the opinion that study concerning the relationship between education and ecological environment should be conducted. The Taiwanese scholar Fang Binglin proposed in the book of Ecological Environment and Education that study concerning various ecological environment and the education relations and influences on educational system. Chinese scholars Wu Dingfu and Zhu Wenwei put forward in the book of Educational Ecology that above two systems should be combined. Moreover, starting from the interaction between education and the surrounding ecological environment, and analyze the ecological structures and ecological functions. In addition, with ecological system being the focus, set up network system structure, thus focusing on the principle and revealing the basic laws of education ecology. This paper also prefers the view held by Chinese scholars Wu Dingfu and Zhu Wen wei.

Structure OF Education Ecology. Education ecology structure concerns macroscopic and microscopic aspects. The largest macro ecological range of education is ecosphere. The next range is 
the big ecosystem in different countries of the world. It mainly studies various environmental system centered on education, analyzes the function and interaction between education and humans, and seek for the direction of educational development, education system and various countermeasures. The micro ecology of education narrows down to schools, classrooms, equipment and the distribution of seats in classrooms, and also includes micro system analysis such as curriculum setting goals, methods and evaluations. It also narrows down to family relationship, relationship between teachers and students in school, students personal living space and influence of the psychological state on education. This paper manly discusses the network course design under the view of microcosmic education ecology.

Ecological Functions of Education. Ecological functions of education are different from educational functions. But they also overlap. Education ecological system is a system with a specific purpose, which concerns external and internal ecological functions. The internal function is cultivation, and the external function is the social functions - - assisting individual socialization and enabling people to create common values[4].

\section{Enlightenment of Education Ecology on Web-course Construction}

Improving Learning Efficiency. Enhancing instructor feedback effects. Through the investigation on network learning, instructors behavior of students' expectations are concluded: feedback information from instructors ( $22 \%$ ), subject discussions with instructors(19\%), sense of humor(12\%). Other types of expectant behaviors from instructors are uploading videos (9\%), encouragement (7\%), sending emoticons (6\%), setting up personal file (5\%), and sharing life experiences (3\%)[5]. We can see that instructors' feedback has the most influence on students. Instructors ' feedback not only help the learners to solve current problems, but also can help them to find and correct the mistakes in studies, adjust status and progress in their learning and study, and complete assignments using reason methods. Therefore, instructors need to provide timely and abundant feedback information to students.

Improving learners' self-monitoring. From the perspective of ecology, network course is a self-organizing behavior. Students' are the main factor in the system. They are of great significance. Therefore, we should give full play to self-organizing function of students, and actively and consciously monitor and control learning process in learning activities. Learning process is a kind of self- adaptive feedback. In the process, students use a variety of methods to monitor their learning tasks, methods, and objectives. Moreover, through constant feedback information, students adjust learning strategies according to their actual conditions.

Promoting the sustainable learning. The core of network course design is to promote the sustainable development of learning. Different growing environment and experiences of different students cause great differences in their learning motivations, styles, and attitudes. Therefore network course design should pay enough attention to their differences. In addition, according to their different ecological characteristics, they should formulate and design teaching methods appropriate to different students in order to promote and encourage students common development. This requires instructors to provide active guidance and enable students to communicate, inquire, and explore in their studies. It can promote the sustainable development in students' learning and help them obtain the capability of lifelong education[1].

Optimizing ecological information, promoting individual growths. Establishing ecological ideas, promoting individual growths. Educational ecological philosophy mainly focuses on students' growth. Ecological classes should pay attention to quality of survival, quality of life, and students' life development. It requires instructors to provide guidance for students and enable them to learn, communicate and respect other people, in order to help them form active attitudes and good habits in studies.

Improving learning process, optimizing learning contents. Learning is a very complicated process. Optimizing learning contents is of great importance for students to study more effectively. In the design of course contents, various restriction factors may occur. Instructors should analyze its 
limitations and figure out ways to remove the negative influences. Through this approach, the quality of network courses can be improved. In addition, students can only withstand a limited amount of study contents. So they need to formulate their study strategies based their own actual capabilities. We should give full play to humane knowledge and emotional factors contained in network courses in order to help students form correct views and outlooks on life and values. Moreover, the design of network course should make reasonable use of various multimedia approaches and conform to visual principle of human eyes.

Improving ecological environment, promoting the development of online course. Online courses should not only attach importance to the design of the physical environment, but also spiritual development. The design of the physical environment is helpful to students' development in their mentality. When designing online course contents, the layout of the contents should be considered and leave a good and deep impression on students. Successful online courses can not only attract students' attention, but also improve students' efficiency. Moreover, we should make full use of multimedia information, and give full play to the specialty of Internet media. We need to use words, pictures, video, audio, animation and other forms of multimedia approaches so as to present learning contents in the most direct way. Multimedia should also conform to students' learning process. Last but not least, we should extend learning resources combined with course design and students' thinking patterns.

\section{Conclusion}

Physical environment design is the basis for network course design. Spiritual environment design is an important element for measuring the quality of course contents. Therefore, the construction of ecological network course also should focus on creating a harmonious environment. Firstly, we need to ensure the smooth communication between students and teachers. Teacher should provide timely guidance to students and arouse their interests in course contents. Students also need to communicate with each other and seek for mutual and common development. It can help students feel the sense of belonging during their studies. In addition, course design should reflect teaching concepts, and establish scientific learning objectives and clear the learning process, as well as give full play to the initiative and creativity in network content. Lastly, online courses should reflect humanistic care and focus on students' growth. Therefore, course design should be student-oriented, promote students' active learning and healthy growth, thus laying solid foundation for students' lifelong development.

\section{Acknowledgements}

This work was supported by the project "Beijing Higher Education Young Elite Teacher Project". The project number is "yetp1534".

\section{References}

[1] Shi Chuanzhu, Li Dongyu. Classroom Teaching Strategy in Ecology of Education [J] Middle School, 2011, 29 (9).

[2] Wu Dingfu, Zhu Wenwei. Ecology of Education [M]. Nanjing:Jiangsu Education Press, 1990.

[3] Encyclopedia entry: ecology of education:[EB/OL].http://www.hudong.com/wiki/\%E6\%95\% 99\%E8\%82\%B2\%E7\%94\%9F\%E6\%80\%81\%E5\%AD\%A6.

[5] Ma Meng. Research on teachers' Behavior Influences on Learning motivation in Online Courses J]. Chinese Audio-Visual Education, 2011 (1): 66-70.

[6] Sun Jimin.Self-monitoring Learning Theories. Northwest Normal University Paper: Social Science Edition, 2000 (5). 
[7] Peng Haoxiang. Main Characteristics of Effective Teaching Feedback j] Education research and experiment, 2009 (3): 64-66. 